\title{
Sedimentary Characteristics of Stromatolites in Cambrian Strata in Songzi Liujiachang Area and Its Paleoenvironmental Significance
}

\author{
Mei Chen' ${ }^{1}$, Chuantao Xiao ${ }^{1 *}$, Jun Cheng ${ }^{2}$, Xilin Hu1 ${ }^{1}$, Dongquan Sun ${ }^{1}$ \\ ${ }^{1}$ College of Earth Sciences, Yangtze University, Wuhan, China \\ ${ }^{2}$ University of Chinese Academy of Sciences, Beijing, China \\ Email: meichen0826@163.com, *ctxiao@yangtzeu.edu.cn
}

How to cite this paper: Chen, M., Xiao, C.T., Cheng, J., Hu, X.L. and Sun, D.Q. (2018) Sedimentary Characteristics of Stromatolites in Cambrian Strata in Songzi Liujiachang Area and Its Paleoenvironmental Significance. Open Journal of Yangtze Gas and Oil, 3, 79-92.

https://doi.org/10.4236/ojogas.2018.32007

Received: August 17, 2017

Accepted: April 25, 2018

Published: April 28, 2018

Copyright $\odot 2018$ by authors and Scientific Research Publishing Inc. This work is licensed under the Creative Commons Attribution International License (CC BY 4.0).

http://creativecommons.org/licenses/by/4.0/

\begin{abstract}
Stratiform, irregularly stratiform and columnar stromatolites are found in the third section of Qingjiamiao Group, while columnar and hemispherical stromatolites are found in Sanyoudong Group in Cambrian strata in Songzi Liujiachang area. 1) From the stratiform and columnar stromatolites to hemispherical stromatolites, the internal plaster content is decreasing. And from obvious layer characteristics to intermittent layer characteristics, they reflect that the hydrodynamic conditions are strengthening gradually. 2) From the perspective of sedimentary petrology and the classification of stromatolites, it is concluded that the combinations of stromatolites in different sedimentary environments are different and the main sedimentary facies of different types are different: a) Stratiform (including irregularly statiform) and columnar stromatolites are mainly distributed in the upper tidal zone; columnar and hemispherical stromatolites mainly distribute in the intertidal zone. b) The stratiform stromatolites are mainly found in the upper tidal zone with weak hydrodynamic conditions, while the columnar and hemispherical stromatolites are mainly found in powerful hydrodynamic conditions of the lower intertidal zone. 3) A mass extinction of part of the metazoan is the main reason for the growth of stromatolites in Cambrian strata in Songzi.
\end{abstract}

\section{Keywords}

Stromatolites, Songzi Liujiachang Area, The Cambrian Strata, Sedimentary Characteristics, Paleoenvironmental Significance, Hydrodynamic Condition

\section{Introduction}

The stromatolites are widely found in Precambrian strata, and their developmental 
characteristics are largely influenced by the environment, so their sedimentary features are widely used to indicate the depositional environment at that time, as in [1] [2] [3]. After the Phanerozoic, due to the competition of the metazoan and other eukaryotes, environmental factors, and so on, the stromatolites declined rapidly [4] [5] [6]. Therefore, the stromatolites grown in Songzi Liujiachang area in Cambrian strata have great paleoenvironmental significance.

Stromatolites are mainly affected by the microbial community and the environment. The environment will modify the shape of microbial seats, and thus it will affect the developmental characteristics of stromatolites; at the same time, the environment controls microbial community composition, and will indirectly affect the formation of stromatolites as in [7]. Gray and Thorne [8] argue that the distribution of stromatolites species is significantly influenced by the environment by studying the sedimentology of Duck Creek dolomites and referring to the geological data in other areas. Many research results [9]-[14] in Precambrian strata indicate that the type of stromatolites (mainly morphological classification) reflects the depositional environment at that time. This paper focuses on the influence of the environment, and inverts its ancient environment from the perspective of sedimentary petrology. According to the internal composition characteristics of different forms of stromatolites, the rock composition and the associated sedimentary structure of their surrounding rock, the sedimentary environment of different types of stromatolites is deduced [15].

\section{Regional Profile}

Liujiachang town is located in the southwest of Songzi, Hubei Province, and it is in the Yangtze river basim. In the research area, the Cambrian sequence is complete and widely distributed; the outcrop is good, and it is distributed around Songzi Liujiachang anticline [16]; the lower Cambrian strata is divided into Shuijingtuo Group, Shipai Group, Tianheban Group and Shilongdong Group from bottom to top. The middle and upper Cambrian strata develops better, regarding Songzi Liujiachang as the representative, which is divided into Qinjiamiao Group and Sanyoudong Group. Lithology, mainly carbonate rocks with less clastic rocks, mainly developed in the lower part of the lower Cambrian strata. Stromatolites in the Cambrian period were found in the third section of Qingjiamiao Group and Sanyoudong Group in middle and upper Cambrian strata, located in Jinzhuyuan, Shuilvtang and Lvtang, Xinshendong, Luanshutang, Xijiapo and other places. They are mainly the restricted platform carbonate deposition [17]. The following are the stratigraphic characteristics of the Qinjiamiao Group and the Sanyoudong Group.

The Qinjiamiao Group is located at the core and two wings of the anticline in Liujiachang. The lithology is mainly composed of a set of light gray, gray, dark gray, thin to medium thick dolomite, dolomitic limestone, argillaceous dolomite containing grayish yellow, yellow-brown, thin to mid-feldspar quartz sandstone, and the lower part is covered. The exposed thickness is about $300 \mathrm{~m}$. According 
to its lithology, it can be divided into the following four sections.

The first section: Gray, light gray and thin to medium and thick layer of dolomite, muddy dolomite. The lower part is characterized by grayish yellow, thin layer and muddy clay, and it contains rock salt pseudomorphic and gypsum pseudomorphic. The upper part is characterized by gray, light gray, medium-thick layered mud-powder dolomite. This section's thickness is about $100 \mathrm{~m}$.

The second section: grayish yellow, tawny and thin to medium layer feldspar quartz sandstone. Its thickness is about $5-10 \mathrm{~m}$, with its outcrop weathering intensively. The feldspar has been weathered into white spots kaolinite.

The third section: gray to dark-gray and medium to thick layer of dolomitic limestone, dolomite, with a small amount of muddy dolomite. It structure is mainly mud crystal - powder, with several layers arenite, gravel, powder crystal dolomite and dolomitic limestone. More stratiform, columnar stromatolites are found in this section. Its thickness is about $80 \mathrm{~m}$.

The fourth section: light gray, grayish yellow and medium to thick layer dolomite, muddy dolomite and dark gray and medium to thick layer dolomite. They are interbeded, distinguished with Sanyoudong Group above by three-meters' yellow muddy dolomite at the top.

Sanyoudong Group are mainly distributed in the southern and northern wing of Liujiachang anticline. This group is mainly a set of light gray, gray-black and thick layer to block powder crystal - fine dolomite, with arenite, gravel dolomite and siliceous band. At the top is the gray thick layer grainstones with light gray thin layer dolomite. Cross bedding can be found typically; columnar and hemispherical stromatolites can be found, and its thickness is $300 \mathrm{~m}$ [17] (Figure 1).

\section{The Types and Sedimentary Characteristics of Stromatolites in Cambrian Strata}

In this paper, according to the predecessors, the stromatolites in the research area are classified into stratiform, statiform to columnar, columnar and hemispherical stromatolites. The classification is mainly based on the morphological characteristics. Sedimentary characteristics, i.e. the characteristics of the surrounding rock; the internal and distributional characteristics of stromatolites, as well as the accompanied sedimentary structure of stromatolites in different Groups, were described specifically in order to provide evidence to estimate the sedimentary environment.

\subsection{Stromatolites Types}

Stromatolites are classified and distinguished according to their morphological characteristics. According to the layered stacking way, they are lateral disconnection dome, lateral connection dome and mutual wrapping type. The stromatolites are divided into columnar, stratiform and stratiform to columnar and combining stromatolites. The shape of the column can be divided into 




Figure 1. The column diagram and the vertical distribution of the stromatolites in Cambrian strata in Songzi Liujiachang area.

regular sub-cylindrical, irregular sub-cylindrical, false cylinder, tuber, cone and inverted vertebral body, as in [4] [18] [19]. Based on the classification and internal structure characteristics above, the stromatolites in Cambrian strata in this research area are divided into stratiform, stratiform to columnar, columnar and hemispherical stromatolites.

The stromatolites in Qinjiamiao Group in the middle Cambrian strata in Liujiachang area are stratiform or irregularly stratiform or columnar stromatolites (Figures 2(a)-(d)). The stromatolites in Sanyoudong Group in the upper Cambrian strata are columnar and hemispherical stromatolites (Figure 2(d) \& Figure 2(e)). 


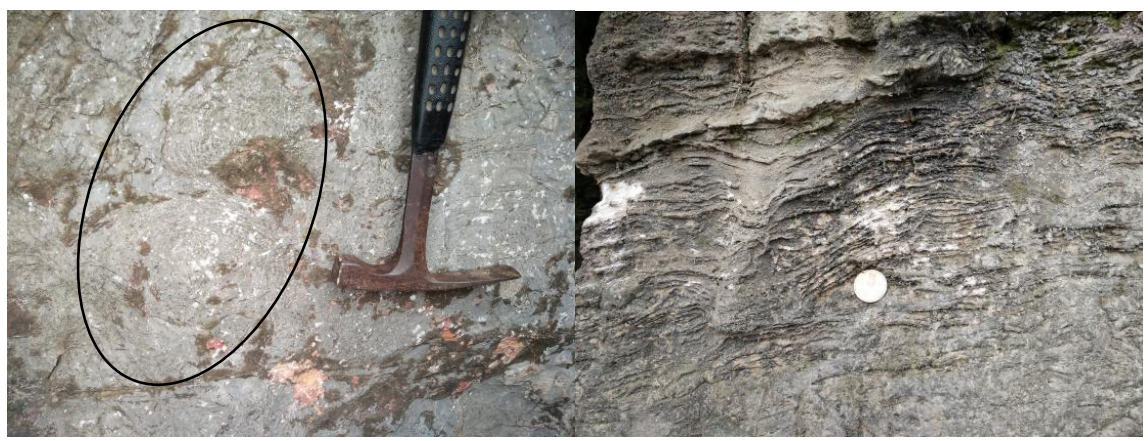

(a)

(b)

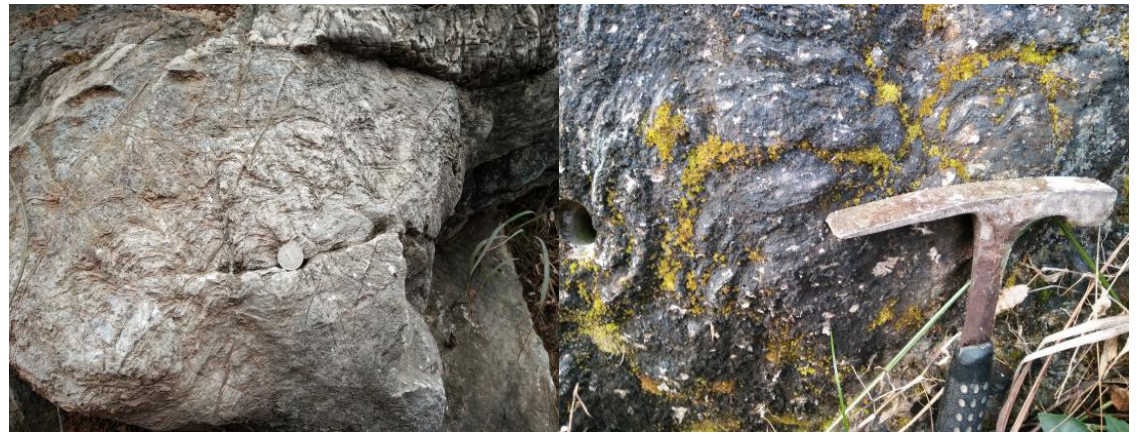

(c)

(d)

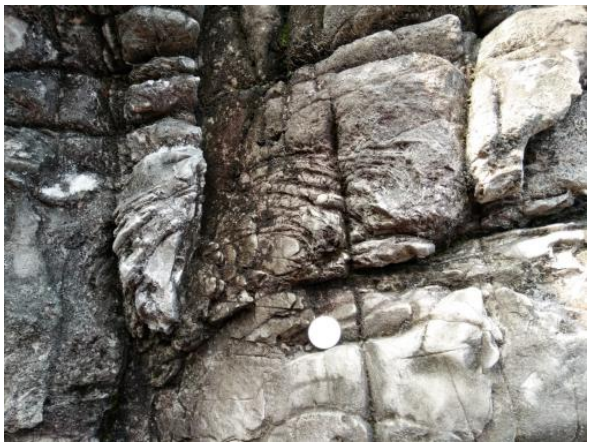

(e)

Figure 2. (a) stratiform and columnar stromatolites in Qinjiamiao Group (top view); (b) stratiform stromatolite in Qinjiamiao Group; (c) irregularly stratiform and columnar stromatolites in Qinjiamiao Group; (d) columnar stromatolite in Qinjiamiao Group; (e) hemispherical stromatolite in Sanyoudong Group. Plate: The field characteristics of Cambrian stromatolites in the Liujiachang area of Songzi.

\subsection{Stromatolites Sedimentary Characteristics}

As for stromatolites in the third section of Qinjiamiao Group, the surrounding rocks are gray to dark gray and medium to thick layer of dolomitic limestone, dolomite. By clipping a small amount of muddy dolomite, there develops diminutive stromatolites continuously or discontinuously. Their average thickness is about $0.5 \mathrm{~m}$. The stromatolites are stratiform, irregularly stratiform, and columnar stromatolites which can be found nearby. 1) The scale of the stratiform stromatolites is large, and the layer is obvious. In the lower part, more bright lamina has grown and the layer is dense; in the upper part, melanic 
lamina has relatively grown and the layer gradually becomes gently upward (seen in Figure 2(a), Figure 2(b)); 2) The growth of irregularly stratiform stromatolites is more limited, and the layer is not obvious, extending horizontally far, only about $0.1 \mathrm{~m}$ in the longitudinal direction. The erosion surface can be found in the lower part, which may represent a process of hydrodynamic strengthening (seen in Figure 2(c)); 3) The columnar stromatolites are irregularly sub-cylindrical, and their thickness is larger. The melanic lamina develops and it is not continuous (seen in Figure 2(a), Figure 2(d)). The structure is mainly composed of mud crystal - powder crystal with several layers of sand debris, gravel debris and powdered scrap dolomite and dolomitic limestone. The salt pseudomorphic and gypsum pseudomorphic rocks can be found in the Qinjiamiao Group, reflecting the upper tidal zone exposed intermittently with lower energy.

As for the Stromatolites in Sanyoudong Group: stromatolites are columnar and hemispherical, with small thickness and relatively limited extention. The sparry calcite can be seen. Bright lamina grows in the hemispherical stromatolites, which shows intermittently bright and melanic lamina alternately, with the layers thinning to disappear and the width becoming smaller (seen in Figure 2(e)). The columnar stromatolites are similar to stromatolites in Qinjiamiao Group. The surrounding rock is mainly composed of a light gray, gray-black and thick layer to the massive powdery crystal to fine dolomite, with arenite dolomite, dolorudite and siliceous stripes. It's the gray and thick layer of grain limestone with light gray and thin layer of dolomite. Cross bedding can be seen locally, which reflects the depositional environment of the intertidal zone with powerful energy.

\section{Sedimentary Environment Distribution Patterns of Stromatolites in Precambrian Strata}

\subsection{Discussion about Paleoenvironmental Significance of Stromatolites in Precambrian Strata}

Donldson [20] measured five sections of the Dismal Lake Group in Precambrian strata in Canada and found a significant correlation between the morphological changes of stromatolites and the original sedimentary structures. He also explained the environment during the formation of the stromatolites (seen in Table 1). The conclusion seems to have been recognized by the stromatolites experts [4]. Awramilk [12] argued that many Proterozoic columnar stromatolites may be formed under the subtidal environment; the stromatolites in Prephanerozoic Eon and Phanerozoic Eon are usually formed in a periodically exposed environment. It has been found that Cyanobacteria fossils similar to those of Lyngbya are present in the stromatolites layers, and the molecules of the genus usually live in sub-aerobic environments, which is in correspondence with the view that the stratiform stromatolites grew in semi-exposed environment [4]. The above is the main research results of the relationship between certain 
morphological features and special environment of stromatolites, which shows the significance of stromatolites morphology for environmental research.

At the same time, Grotzinger [13] found that the Proterozoic platform shows little difference with Phanerozoic in the total phase of the construction and morphology. So the way in which we have analyzed sedimentary environment of stromatolites in Proterozoic strata is of great importance to study the environmental significance of stromatolites in the Phanerozoic strata.

Table 1. Different forms of stromatolites and associated structure. The structures in the figure are from the left to the right representing the wave marks, the cross bedding, the oolitic, the rock salt pseudomorphic and gypsum pseudomorphic, the dry crack layer and the intraformational breccia [20].

\begin{tabular}{|c|c|c|c|c|c|c|c|c|c|c|c|}
\hline \multirow{2}{*}{ Stromatolies form } & \multicolumn{6}{|c|}{ Contact structure } & \multicolumn{2}{|c|}{ Turbulence } & \multicolumn{3}{|l|}{ Under the tide } \\
\hline & $ح$ & $\overline{I I I}$ & () & 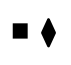 & 人 & $1 / 11$ & low & high & trice & tis & On the tide \\
\hline$\approx$ & & & & $\checkmark$ & $\sqrt{ }$ & $\sqrt{ }$ & -- & --- & & & - \\
\hline  & $\sqrt{ }$ & $\sqrt{ }$ & $\sqrt{ }$ & & $\sqrt{ }$ & $\sqrt{ }$ & - & $--\longrightarrow$ & & & - \\
\hline คิ ล $\Omega$ & $\sqrt{ }$ & $\checkmark$ & $\sqrt{ }$ & $\checkmark$ & $\sqrt{ }$ & $\checkmark$ & & - & & & -- \\
\hline$\therefore$ & $\checkmark$ & $\checkmark$ & & $\sqrt{ }$ & & & - & & $-\quad-$ & - & - \\
\hline & $\sqrt{ }$ & $\sqrt{ }$ & & $\sqrt{ }$ & & $\sqrt{ }$ & -- & & & 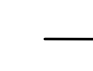 & --- \\
\hline$\theta \sigma$ & $\sqrt{ }$ & $\sqrt{ }$ & $\sqrt{ }$ & & & & -- & -- & -- & & \\
\hline ת & $\sqrt{ }$ & $\sqrt{ }$ & & & & & - & & ---- & & \\
\hline సैబิ & & & & & & & - & & - & & \\
\hline
\end{tabular}

\subsection{Sedimentary Environment Analysis of Stromatolites in Cambrian Strata}

1) Stratiform stromatolites

The stratiform stromatolites appear in the third section of the Qinjiamiao Group with large scale and are accompanied by irregularly stratiform and columnar stromatolites. The internal is algal limestone with bonded structures, which is mainly composed of stucco and has the highest amount of stucco in the stratiform stromatolites. The surrounding rock is mainly composed of dolomitic limestone with little muddy dolomite, which reflects the sedimentary characteristics of the restricted platform facies. The micritic and crystal powder structure is the main component, which reflects the low-energy sedimentary environment. At the same time, the presence of rock salt pseudomorphic and gypsum pseudomorphic is a believable evidence of the exposed surface. According 
to the tidal phase zone model of Laepert, it can be speculated that the stratiform stromatolites grow in the intermittent exposed upper tidal zone.

2) Irregularly stratiform stromatolites

Irregularly stratiform stromatolites are found in the third section of the Qinjiamiao Group. The growth of this type of stromatolites is more limited, the layer is not obvious, extending horizontally far, but only about $0.1 \mathrm{~m}$ in the longitudinal direction. The erosion surface can be seen in the lower part, which may represent a process of hydrodynamic strengthening. Compared with the stratiform stromatolites, the stucco content is reduced and the layer continuity is deteriorated. Since there is a symbiosis between the reduced stucco content and the deteriorated layer continuity in the same stratigraphic section, it can be speculated that the irregularly stratiform stromatolites are found in the upper tidal zone with a slightly stronger hydrodynamic condition than that of the stratiform stromatolites.

3) Columnar stromatolites

The columnar stromatolites are not only found in the third section of Qinjiamiao Group, but also in Sanyoudong Group. And they have fine internal particles, less stucco content and intermittent arrangement of layers. In Sanyoudong Group, the surrounding rock is powder crystal to fine-grained dolomite with arenite, gravel dolomite and siliceous strip. The cross bedding can be seen locally. Based on the morphological characteristics of columnar stromatolites, it can be speculated that the columnar stromatolites are mainly found in the sedimentary environment of the lower part of intertidal zone with powerful energy.

4) Hemispherical stromatolites

Hemispherical stromatolites with the above-mentioned columnar stromatolites are found in Sanyoudong Group. Their scale is small, but their particles are large with almost no stucco. There grows bright lamina, showing intermittent bright, dark layer changes. The layer is tapering to disappearance, and the horizontal width is small. It reflects that hemispherical stromatolites are found in the lower part of the intertidal zone with more powerful hydrodynamic conditions relative to that of the columnar stromatolites.

From the above characteristics of the stromatolites, it can be concluded that from the stratiform, irregularly stratiform, columnar to hemispherical stromatolites, the internal stucco content is decreasing; from obvious layer characteristics to intermittent layer characteristics, it is reflected that the hydrodynamic conditions are strengthening gradually. Moreover, from the perspective of sedimentary petrology, the sedimentary environment of different types of stromatolites is highly consistent with that of the Proterozoic strata.

\subsection{Sedimentary Environment Distribution Patterns of Stromatolites}

According to the internal characteristics of the various types of stromatolites and 
the rock combinations and sedimentary structure of the surrounding rock in Cambrian strata in Songzi Liujiachang area, by means of the analysis method, method and evidence of the sedimentary environment of the Precambrian stromatolites, it is possible to judge the depositional environment of different types of stromatolites in Cambrian strata in Liujiachang area, and the sedimentary environment distribution pattern is shown in Figure 3.

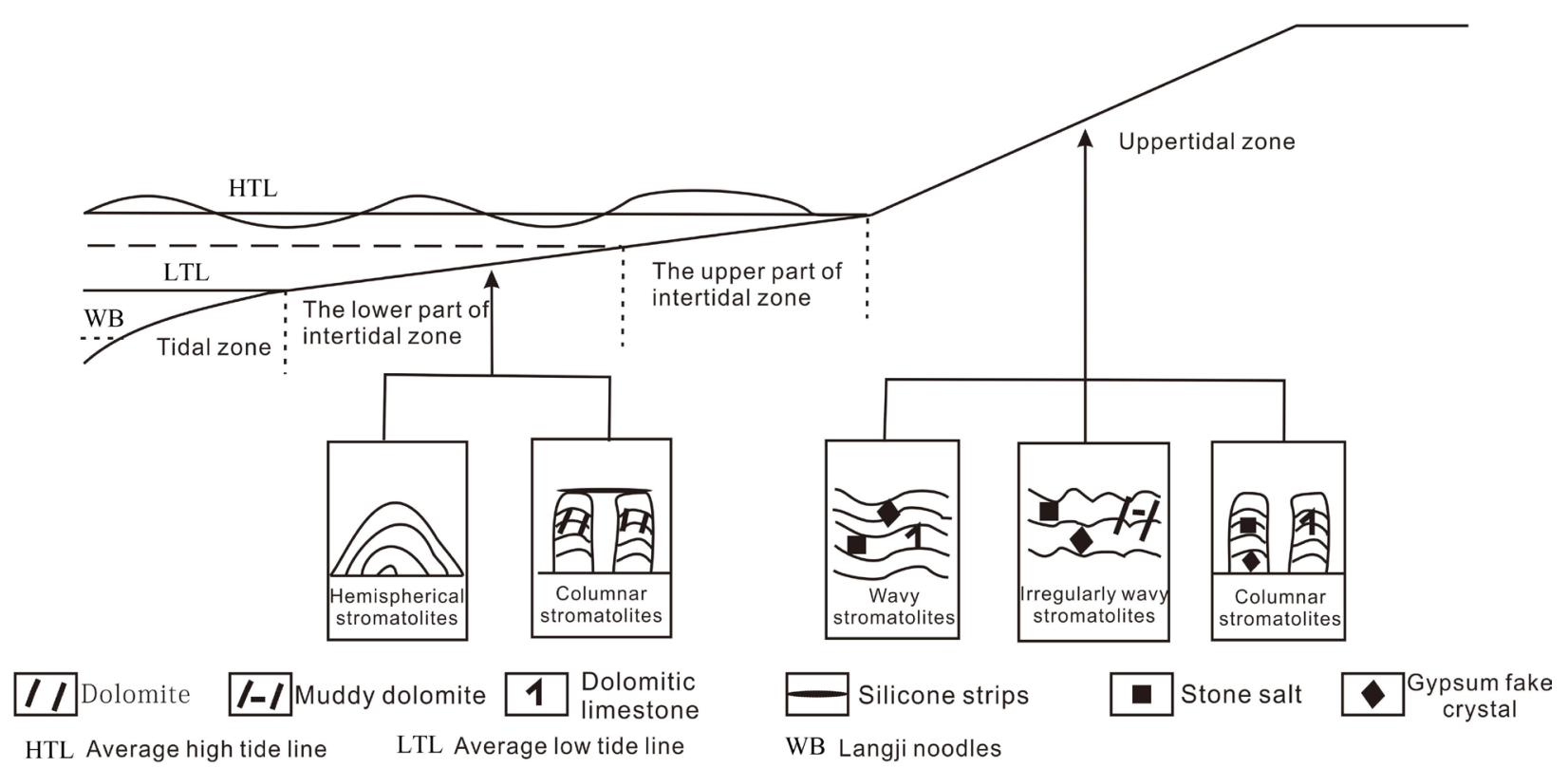

Figure 3. The sedimentary environment patterns of stromatolites in the Cambrian strata in Songzi Liujiachang area.

From the picture of the sedimentary environment distribution patterns of the stromatolites, it can be seen that the stromatolites in Songzi Liujiachang area are mainly grown in the tidal environment. The sedimentary facies of the stromatolites can be divided into different sedimentary facies zones according to their different sedimentary environmental characteristics:

1) The main stromatolites in the upper tidal zone are stratiform, irregularly stratiform stromatolites and stone, with a small amount of columnar stromatolites and stone. There is a lot of plaster inside the stromatolites, and the layer is obvious. It is accompanied by rock salt pseudomorphic and gypsum pseudomorphic, reflecting the upper tidal zone with the intermittent exposure to the environment and a weak hydrodynamic energy;

2) The stromatolites in the intertidal zone are mainly columnar stromatolites and hemispherical stromatolites. The internal particles of the stromatolites are larger, with the arene and the gravel. The laminas are intermittently arranged; the content of the stucco is small; cross bedding can be seen locally, reflecting the lower part of the intertidal zone with strong hydrodynamic conditions.

The paleoenvironmental significance of different types of stromatolites in the research area can be concluded as follows. The stratiform (including irregularly stratiform) stromatolites mainly grow in the upper tidal zone with weak 
hydrodynamic conditions; the columnar and hemispherical stromatolites are mainly found in the lower part of the intertidal zone with strong hydrodynamic conditions.

\section{Discussion on the Cause of Formation of Stromatolites in Cambrian Strata in Songzi}

Stromatolites macromorphology (including reefs and stromatolites cylinder) can be mostly influenced by the environment, and the finer features are mainly affected by the original organism [20]. The impact of hydrodynamic conditions in the environment on the macromorphology of stromatolites is analyzed above. At the same time, the original organism in the construction of the stromatolites (ie stromatolites germs) are also important controlling factors. The growth of the stromatolites is inseparable from the environment of stromatolites microbes. More importantly, the growth of stromatolites in Cambrian strata in the Liujiachang area was at the beginning of the re-prosperity period of microbialite. At the end of the middle Cambrian, it is a response on the Yangtze massif of the re-prosperity period of global microbialite, and it is of great significance to explore the interrelationship between the biological evolution and the environmental change.

1) Microbes factor

At the end of the early Cambrian, the extinction of the biological cluster (the Sinsk incident and the Toyonian event) resulted in the mass extinction of the prosperity of archaeocyatha and sponges, while the calcareous cyanobacteria cluster began to grow and multiply. From the Middle Cambrian to Early Ordovician period, the stromatolites built by Renalcis, Epiphyton and filamentous Girvannella, were widely distributed in the shallow carbonate platform environment [21]. At present, it is believed that the relationship between the metazoan and microbial rock is shifting. Recently, some scholars have proposed a more complex dynamic equilibrium coupling [22], but a large reduction of the metazoan will eventually lead to microbial growth and breeding. It can be speculated that the mass extinction of part of the metazoan in the early Cambrian strata has caused the growth and breeding of the stromatolites germs, which is an important reason for the re-prosperity of the stromatolites.

2) Environment factor

High sea level peak and high carbon dioxide partial pressure of the atmosphere in the middle Cambrian strata will result in the increase of metabolic energy consumption of organisms and the reduce of sea water oxygen content, which is beneficial to the growth and development of cyanobacteria and calcification, which have inhibited the metazoan's life [21] [22] [23] [24] [25]. From the above research results, it can be seen that the environmental factor eventually leads to a mass reduction of the metazoan and a mass reproduction of microbes, thus making microbial rock prosperous.

On the Yangtze massif, the archaeocyatha-microbial reefs which grew in the 
early Cambrian strata disappeared in the middle Cambrian strata; and the metazoan fossils were rare in the middle and late Cambrian strata [21] [26] [27]. At the same time, the stromatolites in the third section of Qinjiamiao Group in Songzi Liujiachang area in Yangzi area in the late Cambrian strata grew when part of metazoan became extinct largely and the stromatolites microbes became prosperous largely at the end of the middle Cambrian strata. It can be speculated that the mass extinction of some metazoan, the main reason for the growth of stromatolites of Cambrian strata in the research area, has made the growth and reproduction of stromatolites microbes.

\section{Conclusions}

In this paper, the sedimentary environment of different types of stromatolites was discussed from the perspective of sedimentary petrology in terms of the internal characteristics of different types of stromatolites, the nature of surrounding rock, the associated sedimentary structures and so on. Their environment was verified according to the research results of Proterozoic stromatolites, and the sedimentary environment distribution patterns of stromatolites in Songzi Liujiachang area were summed up.

The stromatolites in Cambrian strata in Liujiachang area are stratiform, irregularly stratiform, columnar to hemispherical stromatolites. Their internal plaster content was reduced and lamina characteristics were presented from obvious to intermittent, reflecting a changing environment with strengthening hydrodynamic conditions.

The same type of stromatolites can exist in different depositional environments, such as columnar stromatolites, which are found in the upper tidal zone and intertidal zone in the research area. All in all, different stromatolites combinations in different sedimentary environments in the research area are different, and the main sedimentary facies of different types of stromatolites are different. 1) Stratiform, irregularly stratiform and columnar stromatolites are mainly distributed in the upper tidal zone; columnar and hemispherical stromatolites are mainly distributed in the intertidal zone. 2) The stratiform stromatolites (Including irregularly stratiform) mainly grow in the upper tidal zone with weak hydrodynamic conditions, while the columnar and hemispherical stromatolites are mainly found in powerful hydrodynamic conditions of the lower intertidal zone.

Furthermore, a mass extinction of part of the metazoan is the main reason for the growth of stromatolites in Cambrian strata in Songzi.

\section{Research Prospects}

Stromatolites' significance in the environment is in the process of being known constantly, but it has not yet formed a unified point. In this paper, we focused on the stromatolites in the Cambrian strata in Songzi Liujiachang area, and we discussed paleoenvironment of stromatolites in terms of their internal charac- 
teristics, surrounding rock properties, sedimentary structure and so on, which has great reference significance. However, the environment is not the only constraint factor in stromatolites' characteristics, we can't directly regard macromorphology of stromatolites as an environmental indicator at the time of reference [28] [29]. At the same time, microbial communities also have an important effect on the morphology of the stromatolites [7] [30] [31] [32]. In the research and the application, the deposition of petrology, paleontology and other aspects should be combined to consider paleoenvironmental significance of stromatolites. The stromatolites in the research area is the response to the re-prosperity of global microbial rock in the Yangtze block, which is expected to provide a new pointcut for exploring the relationship between biological evolution and environmental change.

\section{Acknowledgements}

We would like to thank Xiao Chuantao, Cheng Jun, Hu Xilin and Sun Dongquan for helpful discussions. This work is supported by the Natural Science Foundation of China (No. 41572322) and by Innovative Training Program for College Students in Yangtze University (No. 2016013).

\section{Fund Projects}

National Natural Science Foundaction of China (No. 41572322) and Innovative Training Program for College Students in Yangtze University (No. 2016013).

\section{References}

[1] Qian, M.P. (1991) Environmental Significance of Sinian Algal Stromatolites in Northern Jiangsu and Anhui, China. Palaeontological Journal, 30, 616-630.

[2] Li, X., Luo, S.S., Kuang, H.W., Men, F.X. and Chang, J.J. (2008) Stromatolite Deposition and Depositional environment in Wumishan Formation of West Liaoning. Special Oil and Gas Reservoirs, 15, 41-48.

[3] Gotzinger, J.P. and Knoll, A.H. (1999) Stromatolites in Precambrian Carbonates: Evolutionary Mileposts or Environmental Dipsticks? Annual Review of Earth and Planetary Sciences, 27, 313-358. https://doi.org/10.1146/annurev.earth.27.1.313

[4] Cao, R.J. and Yuan, X.L. (2006) Stromatolites. 1st Edition, University of Science and Technology of China Press, Hefei.

[5] Chen, L.Q. (2007) A Review of the Mechanism of Stromatolite Decline in the Geological History. Xinjiang Geology, 25, 365-367.

[6] Mei, M.X., Gao, J.H., Meng, Q.F. and Liu, Z.R. (2008) Microdigital Stromatolites and their Response to Stromatolite Decline at 1 250, Ma \pm for the Mesoproterozoic Wumishan Formation at Jixian Sectionin Tianjin. Journal of Palaeogeography, 10, 496-509.

[7] Zhang, Y. and Hoffmann, L. (1992) Blue-green Algal Mats of the Salinas in San-Ya, Hai-Han Isand (China): Structure, Taxonomic Composition and Implications for the Interpretation of Precambrian Stromatolites. Precambrian Research, 56, 275-290. https://doi.org/10.1016/0301-9268(92)90105-W

[8] Grey, K. and Thorne, A.M. (1985) Biostratigraphic Significance of Stromatolites in 
Upward Shallowing Sequences of the Early Proterozoic Duck Creek Dolomite, Western Australia. Precambrian Research, 29, 183-206. https://doi.org/10.1016/0301-9268(85)90068-3

[9] Pratt, B.R. (1982) Stromatolitic Framework of Carbonate Mud Mounds. J. Sedim. Petrol., 52, 1203-1227.

[10] Semikhatov, M.A. (1976) Experience in Stromatolite Studies in the USSR. In: Walter M R, Ed., Stromatolites. Developments in Sedimentology, 20. Elsevier, Amsterdam, 337-358. https://doi.org/10.1016/S0070-4571(08)71143-9

[11] Hoffman, H.J. (1976) Precambrian Microflora, Belcher Islands, Canada: Significance and Systematics. Journal of Paleontology, 50, 1040-1073.

[12] Awramik, S.M. (1984) Ancient Stromatolites and Microbial Mats. Microbial Mats: Stromatolites. Alan R. Liss Inc., New York, 1-22.

[13] Grotzinger, J.P. (1989) Facies and Evolution of Precambrian Carbonate Depositonal System: Emergence of the Modern Platform Archetype. In: Crevello, P., Read, J.F., Sarg, R. and Wison, J., Eds., Controls on Carbonate Platform and Basin Development, SEPM Special Publication, 44, 79-106. https://doi.org/10.2110/pec.89.44.0079

[14] Walter, M.R., Grotzinger, J.P. and Schopf, J.W. (1992) Proterozoic Stromatolites. In: Schopf, J.W. and Klein, C., Eds., The Proterozoic Biosphere, a Multidisciplinary Study, Cambridge University Press, 253-260.

[15] Chang, Y.G., Qi, Y.G., Zheng, W., Wang, M. and Dai, M.Y. (2013) Sedimentary Characteristics and Paleoenvironmental Significance on Stromatolites of Mantou Formation in Cambrian, Western Henan, China. Acta Sedimentologica Sinica, 31, $10-19$.

[16] Wang, X., Zhang, S., Zeng, Q., Xu, G., Zhou, T., et al. (1983) Trilobites in Sanyoudong Group and the Division of the Upper and Middle Cambrian. Chinese Academy of Geological Sciences Yichang Institute of Geology and Mineral Resources Collection, No. 6, 73-98.

[17] Li, J., Gong, W., Liu, X. and Xiao, C. (2013) Guide to Region Geology and Teaching Practice in Songyi Area in Southwest of Hubei Province. 1-43.

[18] Cao, R. (2003) History and Current Status of Study on Stromatolitic Nomenclature and Classification in the Precambrian. Geological Survey and Research, 26, 80-83.

[19] Miao, C. (1986) The Classification of Stromatolites and Related Taxonomic Problem Discussed. Xinjiang Geology, 4, 27-48.

[20] Donaldson, J.A. (1976) Paleoecology of Conophyton and Associated Stromatolites in the Precambrian Dismal Lakes and Rae Groups, Canada. In: Walter, M.R., Ed., Stromatolites Developments in Sedimentology, Elsevier, Amsterdam, 523-534. https://doi.org/10.1016/S0070-4571(08)71156-7

[21] Dang, H., Liu, J. and Yuan, X. (2009) Microbialites in the Middle Cambrian Qinjiamiao Group in Xingshan, Hubei Province: Implication for Paleoenvironmental Reconstruction. Acta Scientiarum Naturalium Universitatis Pekinensis, 45, 289-298.

[22] Chang, Y., Bai, W. and Wang, M. (2017) Evolution Characteristics of Cambrian Stromatolites in Western Henan and the Coupling Relationship with Metazoan. Geoscience, 31, 92-101.

[23] Matthews, S.C. and Cowie, J.W. (1979) Early Cambrian Transgertion. Journal of Geological Society of London, 136, 133-135. https://doi.org/10.1144/gsigs.136.2.0133

[24] Berner, R.A. (1990) Atmospheric Carbon Dioxide over Phanerozoic Time. Science, 249, 1382-1386. https://doi.org/10.1126/science.249.4975.1382

[25] Riding, R. (2006) Cyanobacterial Calcification, Carbon Dioxide Concentrating 
Mechanisms, and Proterozic Cambrian Changes in Atmospheric Composition. Geobiology, 4, 299-316. https://doi.org/10.1111/j.1472-4669.2006.00087.x

[26] Zhang, T., Lan, G., Shen, Z., Wang, S. and Jiang, Z. (2005) Early Cambrian Reefs and Banks Development in Southern Margin of Daba Mt. and Micang Mt. Natural Gas Geoscience, 16, 710-714.

[27] Zhang, J. and Yuan, K. (1994) Archaeocyath Reefs from the Lower Cambrian Tianheban Formation at Wangjiaping, Yichang, Hubei and Their Diagenesis. Geology Science, 29, 236-245.

[28] Walter, M.R. (1977) Interpreting Stromatolites. American Scientist, 65, 563-57.

[29] Monty, C.L.V. (1977) Evolving Concepts on the Nature and the Ecological Significance of Stromatolites. In: Flügel, E., Ed., Fossil Algae, Recent Results and Developments, Springer-Verlag, Heidelberg, 15-35. https://doi.org/10.1007/978-3-642-66516-5_2

[30] Awramik, S.M. (1976) Gunflint Stromatolites: Microfossil Distribution in Relation to Stromatolite Morphology. In: Walter, M.R., Ed., Stromatolites Developments in Sedimentology, Elsevier, Amsterdam, 311-320.

https://doi.org/10.1016/S0070-4571(08)71141-5

[31] Semikhatov, M.A. and Rabben, M.E. (2000) Proterozoic Stomatonomy and Biostratigraphy. In: Riding, R.E. and Awramik, S.M., Eds., Microbal Sediments, Springer-Verlag, Heidelerg, 295-306.

[32] Cao, R., Yuan, X. and Xiao, S. (2001) On Morphogensis of Conophyton Stromatolites Analyses of a Conophyton-Like Specimen form Neoproterozoic Jiudingshan Formation in N. Jiangsu Province, China. Acta Palaeontologica Sinica, 40, 318-329. 